\title{
ACADEMIAS DE TALENTO FEMININO: MEIOS DE EMANCIPAÇÃO OU FERRAMENTAS DE REPRODUÇÃO SOCIAL? ${ }^{1}$
}

Susana Santos*

(D) https: / / orcid.org/0000-0001-5225-6671

\section{Resumo}

Os programas de promoção do talento e liderança direcionados a mulheres têm-se desenvolvido nos últimos anos e acompanham os debates mais alargados sobre a igualdade de género, as diferenças salariais e a conciliação entre trabalho e vida familiar. As sociedades de advocacia, pelo seu carácter internacional e de grande permeabilidade aos discursos na esfera económica global, são um excelente objeto de observação.

Neste artigo, problematizam-se as interseções entre feminismos e neoliberalismo, em especial o feminismo neoliberal e o feminismo transnacional de negócios a partir da observação sociológica da cultura organizacional das sociedades de advocacia de grande dimensão em Portugal.

Palavras-chave: academias de talento feminino; liderança; feminismo neoliberal; feminismo transnacional de negócios; sociedades de advocacia.

\begin{abstract}
Feminine Leadership Academies: emancipation forms or social reproduction mechanisms?

Programs for the promotion of talent and leadership aimed at women have been developed in recent years and accompany the broader debates on gender equality, wage gender gaps and work-life balance. Law firms are an excellent object of observation due to their international atmosphere and their high permeability to discourses in the global economic sphere.

This article discusses the intersections between feminisms and neoliberalism, in particular, neoliberal feminism and transnational business feminism based on sociological observation of the organizational culture of large law firms in Portugal.
\end{abstract}

Keywords: Feminine talent academies; leadership; neoliberal feminism; transnational business feminism; law firms.

Duas versões preliminares foram apresentadas na XIX Conferência Mundial da Associação Internacional de Sociologia (ISA), que decorreu em Toronto, de 15 a 21 de julho de 2018, com o título «Work-Life Balance in Large Law Firms: A Case Study on Young Female and Male Lawyers» e na conferência internacional «Mulheres, Mundos do Trabalho e da Cidadania», organizada pelo Dinâmia'CET-IUL, que decorreu em Lisboa, no ISCTE-IUL, a 6 e 7 de dezembro de 2018, com o título «Grandes sociedades de advocacia enquanto organizações genderizadas: análise dos impactos na socialização e integração profissional de jovens advogadas/os».

Cies.Iscte, Instituto Universitário de Lisboa, 1649-026 Lisboa, Portugal.

Endereço Postal: Avenida das Forças Armadas, 1649-026 Lisboa, Portugal.

Endereço eletrónico: susanacsantos@iscte.pt 


\section{Resumen}

Academias de Talento Femenino: ¿formas de emancipación o mecanismos de reproducción social?

Los programas para la promoción del talento y el liderazgo dirigidos a las mujeres se han desarrollado en los últimos años y acompañan los debates más amplios sobre igualdad de género, diferencias salariales y la conciliación de la vida laboral y familiar. Los despachos de abogacía, debido a su carácter internacional y su alta permeabilidad a los discursos en la esfera económica mundial, son un excelente objeto de observación.

Este artículo analiza las intersecciones entre feminismos y neoliberalismo, en particular, el feminismo neoliberal y el feminismo empresarial transnacional basado en la observación sociológica de la cultura organizacional de las grandes oficinas de abogacía en Portugal.

Palabras-clave: Academias de talento femenino; liderazgo; feminismo neoliberal; feminismo empresarial transnacional; despacho de abogacía.

\section{Introdução}

A liderança no feminino tem sido muito discutida em fóruns nacionais e internacionais, impulsionada por debates mais alargados sobre a igualdade de género, as diferenças salariais e a conciliação entre trabalho e vida familiar. As sociedades de advocacia, ${ }^{2}$ pelo seu carácter internacional e de grande permeabilidade aos discursos na esfera económica global, são um excelente ponto de observação sociológica.

Este artigo pretende problematizar as ligações entre o(s) movimento(s) feminista(s) e o neoliberalismo - a partir da leitura de diversas feministas críticas - e a pesquisa empírica em grandes sociedades de advocacia.

Os programas de formação direcionados em exclusivo às mulheres estão a produzir efeitos? E que tipo de efeitos? Como responde a cultura organizacional?

$\mathrm{O}$ material aqui apresentado foca-se nas atividades desenvolvidas pelas sociedades de advocacia sob o chapéu da diversidade e inclusão, como a flexibilidade de horário e local de trabalho e as academias de talento feminino.

Para tal, foi realizado um conjunto de nove entrevistas a advogadas nos primeiros dez anos de carreira e selecionado um conjunto de documentos produzidos pelas sociedades de advocacia.

A expressão utilizada pelo meio da advocacia é sociedade de advocacia, colocando a referência masculina como universal. Ao longo do texto, e com exceção dos excertos das entrevistas, adota-se uma linguagem inclusiva de acordo com a linha editorial da revista. 


\section{Feminismo neoliberal, popular, pós-feminismo e feminismo transnacio- nal de negócios}

A questão da liderança no feminino e da escassez de mulheres em cargos de topo nos setores público e privado ${ }^{3}$ é indissociável da capacidade de agendamento público do movimento feminista. O debate dos últimos anos tem sido profícuo na criação de termos que pretendem descrever o momento atual, os seus impasses e desafios, apontando ao mesmo tempo novos caminhos. Detenhamo-nos sobre a descrição das dinâmicas sociais entre os movimentos feministas e o modo de organização social prevalecente, isto é, entre feminismos e neoliberalismo. Entende-se neoliberalismo como uma racionalidade política dominante capaz de aplicar a racionalidade de mercado e a sua linguagem de ativos, ganhos, eficácia e eficiência em todas as esferas da vida, incluindo a vida privada (Banet-Weiser, Gill e Rottenberg 2019).

O feminismo neoliberal apropria-se dos conceitos-chave do feminismo - a emancipação, a igualdade - mudando-lhes o significado e introduzindo uma lógica mercantilista na conformação das subjetividades, extraindo-lhes o potencial de transformação social (Rottenberg 2017). A luta por conquistas coletivas é transformada num caminho individual de superação de obstáculos em que o centro da ação é a pessoa capaz de controlar e assumir riscos, ser empreendedora e em que o espaço social é ocupado por um grupo minoritário de mulheres que ascende ao topo profissional à custa do trabalho de mulheres invisíveis e indiferenciadas (Elias 2013). O sucesso profissional é projetado a partir de uma planificação cuidadosa da carreira para assegurar a maior rentabilidade futura baseada na escolha e responsabilidade individual, em processos individuais de tomada de decisão onde a desigualdade de género é um obstáculo a ultrapassar. Exemplo preocupante e extremo é a oferta de serviços de saúde de congelamento de óvulos ou de tratamentos de fertilidade (Kohll 2019) como forma de compensar as funcionárias pelo forte investimento na carreira profissional.

Outro ponto de entrada no debate é através da conceptualização do feminismo mainstream (McRobbie 2009) ou popular (Banet-Weiser 2018). Os media digitais, o cinema comercial, as plataformas de streaming assumem o lugar para a criação sobre temas feministas, concedendo visibilidade que gera retorno através da publicitação do feminismo como um novo modo de consumo, o feminismo como marca, das t-shirts de Frida Kahlo às frases que se tornaram populares em

\footnotetext{
O EIGE - Instituto Europeu para a Igualdade de Género compila os dados relativos à liderança através dos indicadores: mulheres com lugares de CEO, executivas e não executivas em empresas cotadas em bolsa na Europa, em Portugal o índice PSI 20. No primeiro semestre de 2020, em Portugal e na UE a 27 respetivamente: CEO 5,9\% (8,2\% na UE-27), executivas 15,5\% (18,8\%), não executivas 31\% (31\%). Disponível em: https: / / eige.europa.eu/gender-statistics/dgs/indicator/ wmidm_bus_bus_wmid_comp_compex/datatable. Último acesso a 24 de junho de 2020.
} 
marcas como a Zara, ${ }^{4}$ dirigidas ao grande público a preços acessíveis, à afirmação de figuras públicas e celebridades como feministas (Banet-Weiser, Gill e Rottenberg 2019).

O feminismo espetacular das celebridades aliado ao feminismo empresarial publicita e, em simultâneo, invisibiliza as desigualdades, contribuindo para uma naturalização que não ataca as estruturas patriarcais da sociedade. Mulheres como Sheryl Sandberg, chefe operacional do Facebook, são presença nos grandes fóruns internacionais (Davos, Web Summit, etc.), apresentando-se como feministas e defendendo a ideia de que a sua presença no espaço público as coloca no papel de porta-vozes das mulheres (Rottenberg 2014). O seu papel de porta-voz é evidenciado pela publicação de manifestos feministas que rapidamente se transformam em bestsellers. Da análise desses manifestos (Banet-Weiser, Gill e Rottenberg 2019) resulta uma imagem do feminismo como estando em sintonia com a ideologia neoliberal, onde são realçados o sucesso económico, o autocuidado e a conciliação trabalho-família-vida pessoal inseridos numa tendência cultural mais vasta de apologia da felicidade (Rottenberg 2014).

A ideia de felicidade parte da reflexão sobre os riscos de carreiras profissionais diminuídas por conta da maternidade (mummy track), que tem colocado as mulheres perante o dilema «carreira ou família», contrapondo ao ideal de supermulher a de balanced woman que pode optar por uma trajetória profissional não-linear com momentos de investimento diferenciados. A promoção deste tipo de escolhas não tem em consideração a situação profissional e financeira da maioria das mulheres, resultando num projeto feminista elitista que não produz alternativas ao modelo de divisão sexual do trabalho.

Outro exemplo dessa convergência é o destaque dado às mulheres em lugares de poder em instituições nacionais e supranacionais, as femocratas, que atuam como forças sociais legitimadoras do pensamento e ação neoliberal (Roberts 2012; Elias 2013). Nancy Fraser define a corrente progressista neoliberal que esteve por detrás da campanha presidencial de Hillary Clinton como um oximoro (Fraser 2016), no sentido em que aglutina duas forças sociais opostas, de um lado representantes do movimento feminista, do outro lado o capitalismo cognitivo de Wall Street, Silicon Valley e Hollywood. Esta chamada de atenção vem acompanhada de uma proposta feminista que combina as políticas de reconhecimento com as políticas de redistribuição (Fraser 2016) garantindo o carácter emancipatório, intersecional e inclusivo do movimento.

O momento atual beneficia de diferentes dinâmicas convergentes, ou de um pós-feminino de dupla ação (McRobbie 2009) em que os discursos feministas ganham capacidade de se incorporar nas agendas políticas e institucionais, sendo em simultâneo moldado pelas instituições. O resultado é contraditório. A incorporação de temas feministas, em particular a igualdade de género e a liderança no

4 https://www.saberviver.pt/moda/13-t-shirts-feministas-a-apostar. 
feminino, são acompanhadas por formas ativas de despolitização e de essencialização de determinadas categorias e de processos de invisibilização de classe, raça e nacionalidade (Elias 2013).

As iniciativas empresariais partem da ideia de que as mulheres e o espaço doméstico são uma importante oportunidade de negócio e de expansão dos mercados (Goldman Sachs 2009) com a criação de novos serviços pagos, terciarização de funções, criação de novos seguros e comodificação de atividades. O argumento principal desenvolvido pelo gabinete de estudos da Goldman Sachs é que o investimento em mulheres (plataformas de crédito, educação e saúde) é de extrema importância para o desenvolvimento económico e para a expansão das classes médias, em particular nos países BRICS 5 .

Adrienne Roberts (2012) define este tipo de atividades de empoderamento feminino como feminismo transnacional de negócios. O argumento principal surge da forma como a masculinidade de negócios transnacional foi abalada com a crise económica de 2008. No espaço público, foi crescendo a ideia de que são necessárias mulheres em cargos de decisão ${ }^{6}$ e de poder para equilibrar as tensões e a errância masculina, prevenindo assim futuras crises económicas (Roberts 2012, 90). Os argumentos referem as características biológicas, que se manifestam em diferentes traços de personalidade - o mito do género (Elias 2013), com a testosterona associada à agressividade e competição no masculino e o estrogénio ao trabalho de equipa e à aversão ao risco no feminino, a ideia do asset-to estrogen ratio. A maior sofisticação dos argumentos, importando de forma seletiva conhecimento científico, prossegue a estratégia essencialista e reprodutora de estereótipos.

Maria Medina-Vicent (2019) estudou a liderança feminina e o modelo da mulher líder a partir da literatura de gestão especializada. A autora concluiu que o modelo de liderança no feminino é um modelo essencialista, reprodutor de dicotomias de género e com base na racionalidade do homo economicus. Este modelo é apresentado em vários livros de gestão que colocam o problema do número diminuto ou inexistente de mulheres em cargos de topo como um problema individual. A autora sublinha o carácter psicológico das obras, o seu estilo de autoajuda, aspiracional, aliás já identificado por outros autores (Boltanski e Chiapello 1999). A mudança deve ocorrer no interior do indivíduo que se deve superar, vencer os desafios, numa tónica despolitizada e de negação de conflitos. Questões como a maternidade, a conciliação, a igualdade salarial ou a progressão na carreira são apresentadas como momentos de autossuperação.

Acrónimo para Brasil, Rússia, Índia, China e África do Sul.

Ainda recentemente esse argumento foi utilizado a propósito da pandemia COVID-19 e o papel das governantes mulheres (Wittenberg-Cox 2020). 


\section{Sociedades de advocacia: genderização, divisão sexual do trabalho e competição individual}

As grandes sociedades de advocacia são organizações complexas, altamente estratificadas que se posicionam no mercado internacional da prestação de serviços jurídicos (Dezalay e Sugarman 1995). As/os suas/seus profissionais movem-se num mundo global (Faulconbridge e Muzio 2008, 2012) competitivo e diverso. Esta diversidade tem impacto nos processos de seleção e recrutamento das advogadas e dos advogados (Santos 2017, 2018), com uma crescente preocupação de abertura às mulheres, às minorias étnicas, à integração de imigrantes, indo ao encontro das novas especificidades da atividade cada vez mais pautada pelos interesses dos clientes numa ótica do profissionalismo comercial (Hanlon 1998).

No entanto, estas transformações coexistem com desigualdades persistentes e historicamente situadas, como o tardio acesso das mulheres à advocacia ${ }^{7}$, a sua dificuldade em chegar a lugares de topo (Bolton e Muzio 2007) e ainda a contínua reprodução social da imagem do homem branco de classe média como o protótipo do advogado nas sociedades ocidentais (Wilkins e Gulati 1996).

A organização do trabalho, a construção das equipas, a divisão do trabalho, a ocupação dos espaços físicos são processos dinâmicos onde podem ser observadas formas de genderização. Joan Acker define o processo de genderização no interior das organizações como a «vantagem e desvantagem, exploração e controlo, ação e emoção, sentido e identidade moldados em torno de distinções entre homem e mulher, masculino e feminino?» (Acker 1990, 146) que podem ser encontradas na divisão de tarefas, na ocupação dos espaços físicos e nos comportamentos aceites. As questões relativas ao espaço físico ocupado por cada profissional remetem para a relação com a divisão sexual do trabalho e para a prevalência de ocupações femininas e masculinas (Larson 1977).

A genderização das grandes sociedades não corresponde apenas à divisão hierárquica entre a advocacia nas várias posições de carreira, mas de igual modo aos departamentos de suporte, que, em algumas sociedades, têm um número elevado de pessoal técnico de apoio e onde se denota um claro predomínio de mulheres em funções. Existe então uma estratificação ocupacional e por sexo. O número de mulheres em posições de suporte nas sociedades de advocacia perpetua um conjunto de disposições relativas à subordinação das mulheres e ao reforço do seu papel de cuidadoras. Jennifer Pierce explora essas diferenças, assinalando que nas representações das advogadas e dos advogados existem formas de complementaridade nos papéis desempenhados por homens e mulheres que correspondem à ideologia de género cristalizada na ideia de que «as mulheres não possuem um

A primeira mulher a exercer advocacia em Portugal, Regina Quintanilha, iniciou a sua atividade em 1913 e só em 1918 é publicado o decreto n. ${ }^{\circ}$ 4676, de 19 de julho, que permite às mulheres o exercício da profissão. 
instinto assassino para serem advogadas e os homens não possuem as competências sociais para o trabalho paralegal» ${ }^{8}$ (Pierce 1996, 26). Num estudo mais recente sobre o setor financeiro na City de Londres, Linda McDowell (2010) identificou dois padrões de comportamento masculino: os patriarcas - homens mais velhos, racionais e poderosos - e os corretores - homens mais jovens com uma masculinidade exuberante e agressiva, barulhentos e expressivos, com uma confiança heterossexual.

Uma das questões importantes é a de percecionar se a criação de mecanismos de formação direcionados em exclusivo às mulheres, como as academias de talento feminino, estão a produzir efeitos e que tipo de efeitos.

Outra questão importante prende-se com a cultura organizacional das sociedades de advocacia. Nas últimas décadas assistiu-se à promoção da cultura empresarial (Galanter e Henderson 2008), com a divisão das sociedades de advocacia em departamentos autónomos financeiramente, geridos por sócios que acumulam funções de advocacia com a gestão financeira e de pessoal e que são responsáveis pela apresentação de resultados nas assembleias anuais perante o conselho de administração. Cada departamento compete por recursos e, no interior do departamento, cada advogada/o compete para assegurar a promoção ou a manutenção na carreira. Os planos de carreira são delineados tendo em conta um conjunto de parâmetros de avaliação (horas faturáveis, angariação de clientes, formação especializada, participação na vida da sociedade, ensino) e hierarquizam as advogadas e os advogados em cinco a seis categorias (estagiário/a, associado/a, associado/a sénior, associado/a principal, sócio/a de indústria e sócio/a de capital).

Walsh aponta que sociedades que promovem a flexibilidade nos horários, que contam com um maior número de sócios/as e que têm sócias são aquelas que mais promovem oportunidades de promoção na carreira para mulheres ou, de outra forma, que promovem igualmente mulheres e homens (Walsh 2012, 520). No entanto, a autora sublinha que as mulheres que pretendem chegar a sócias são aquelas que dedicam longas horas de trabalho à sociedade, apresentam um total compromisso com a profissão mas que, ainda assim, são consideradas como menos capazes de possuir os requisitos necessários para o sucesso (Walsh 2012, 527).

\section{Análise de dados}

A leitura dos relatórios empresariais e da informação disponibilizada nas páginas de uma seleção de sociedades de advocacia ${ }^{9}$ em conjunto com nove entre-

\footnotetext{
8 Não existe uma tradução para português, mas pode ser entendido pelo conjunto de atividades de suporte da advocacia, como a pesquisa e a escrita sobre um determinado tema jurídico, distinguindo-se da negociação, do contacto direto com clientes e da atividade em tribunal.

9 Foram selecionadas as sociedades de advocacia Cuatrecasas, Uría Menendez - PC (ambas ibéricas com escritórios em Lisboa e no Porto), PLMJ, Morais Leitão, SRS, VdA. Os principais critérios
} 
vistas a advogadas permite traçar um quadro sobre a liderança no feminino, a igualdade de género e as interseções entre feminismo(s) e neoliberalismo em sociedades de advocacia de grande dimensão em Portugal.

Das quatro sociedades portuguesas, duas não fazem qualquer referência às questões de género (PLMJ 2015; SRS 2018); uma - VdA (2019) - destaca a presença de advogadas nos rankings internacionais de liderança no feminino (IRFL1000 2020) e a sua academia de formação com o programa para mulheres executivas Women on Boards; e uma - Morais Leitão - distingue-se pela certificação como empresa familiarmente responsável ${ }^{10}$, um tipo de validação externa que corresponde à elaboração de um plano de conciliação. A informação disponibilizada refere «a igualdade de oportunidades e a liderança e estilos de direção» ${ }^{11}$ mas não adianta como se concretiza.

As duas sociedades ibéricas - Cuatrecasas (2012, 2018) e Uría (2018) - apresentam planos de igualdade com um conjunto de medidas: i) utilização da variável sexo nos processos de recrutamento e promoção; ii) inquéritos de avaliação às condições e satisfação laboral; iii) flexibilidade no horário e no local de trabalho; iv) programas de talento e liderança dirigidas a advogadas nas fases intermédias de carreira que combinam ações de formação internas e externas, com recurso a coaching e mentoring. Os planos destacam ainda a importância da criação de redes e de contactos, apostando no capital social das suas advogadas, como os almoços de negócios no feminino. Reconhecem que o despedimento na categoria profissional de advogado/a atinge de forma diferenciada homens e mulheres, com um predomínio feminino, entre os 30-49 anos (Uría 2018), e que os planos de igualdade têm tido como resultado um crescimento tímido do número de mulheres em cargos de direção (Cuatrecasas 2018).

Os discursos são caracterizados por ideias progressistas em linha com o feminismo neoliberal e mainstream, sublinhando a importância da inclusão de mulheres através do mérito e da capacitação individual.

A análise das entrevistas permite triangular a informação e, em simultâneo, apresentar as representações das advogadas, aflorando estratégias de compreensão das dinâmicas sociais.

de seleção foram: a dimensão (mais de 100 advogadas/os); a atividade internacional; o prestígio entre pares; a facilidade de acesso aos documentos. A certificação é da responsabilidade de uma organização espanhola, a Fundação Más. Mais informação disponível em: https: / / www.masfamilia.org (último acesso a 29 de junho de 2020). Informação disponível em https:/ / www.mlgts.pt/pt/sobre-nos/ responsabilidade-social (último acesso a 29 de junho de 2020). 


\subsection{Ser mulher: estereótipos, competição e superação individual}

Um dos traços que se desenham na análise dos discursos no feminino é a competição entre mulheres na mesma posição. A competição no feminino surge associada a um conjunto de estereótipos sobre o papel da mulher na sociedade como o ser mais submissa, mais cuidadora, mas também mais arranjada, mais preocupada com o aspeto físico e com a opinião dos outros.

Ela tinha um perfil que caía mais nas boas graças dos advogados, era mais submissa, é mais aquela menina capaz de entrar aqui às oito da manhã e sair à meia-noite todos os dias e não pia. Eu defino mais a minha posição, eu gosto de rir, eu estou sempre a falar, eu sou mais reivindicativa. (Estagiária, 26 anos)

Esta aparente divisão em que as mulheres escolhem as outras mulheres como rivais no interior da organização pode ser interpretado como um sinal de desigualdade de género e sobretudo de processos de genderização das profissões (Pierce 1996) e de divisão social do trabalho (Larson 1977). Espera-se coisas diferentes de homens e mulheres e ambos tendem a reproduzir essas expetativas. O quebrar dessas expetativas para as mulheres, que têm um espaço de atuação mais limitado, implica posicionar-se nos pontos extremos, exacerbando características tidas como femininas de cuidar, de multitasking ou de aceitação das regras e ordens expressas pelas hierarquias, procurando não se destacar.

Acho que uma mulher está a trabalhar e a gerir a casa ao mesmo tempo e a atender telefonemas dos filhos e a marcar consultas no médico. Isso também tem que ver com as características das mulheres, somos mais multitasking. Mas é um facto, não vejo os homens a fazerem isso. (Associada, 27 anos)

Ou sublinhando características consideradas masculinas como a liderança e a negociação. Mas se o ser feminino é socialmente aceite no interior da organização, ainda que criticado por algumas mulheres, o mesmo não se passa com as posturas associadas ao masculino, como a ambição e as longas jornadas de trabalho que podem ser expressas como não condicentes com a imagem do que é ser feminino.

Claro que é entendido como uma certa estranheza, sobretudo para as mulheres. Quando é um homem ninguém diz ele é doido, é completamente doido, fica aqui estas horas todas. Quando é uma mulher há esse cunho pejorativo, é completamente passada, fica aqui estas horas todas a trabalhar. Um homem já é uma pessoa dedicada, já é ali um líder, digamos assim. Isso há, pode não ser tão ostensivo, pode não ser dito tão abertamente, mas em conversas em small talk sim. (Estagiária do 3. ${ }^{\circ}$ ano, 26 anos) 
Uma das advogadas conta as dificuldades em afirmar-se como profissional numa fase intermédia da carreira, associada à angariação de clientes. Nesta fase, os homens somam vantagens: 1) a socialização profissional para a liderança, 2) o exemplo dos sócios maioritariamente homens, e 3) uma maioria de clientes homens. Assim, espera-se resultados semelhantes para homens e mulheres quando as condições de partida são desiguais.

Não diria vedados, mas de mais difícil acesso. Eu acho que se tivesse esta conversa com um homem, ele ia achar que não. Na minha experiência pessoal é mais complicado, espera-se o mesmo, mas é mais complicado. Temos que arranjar outras alternativas. (Associada principal, 32 anos)

As advogadas também apontam a dificuldade em ser reconhecidas como líderes, algo que entendem ser considerado um atributo nos advogados.

A mulher sócia é uma mulher que trabalha (...) os homens geralmente fazem mais sala e elas estão mais focadas no trabalho, porque também lhes é imposto, porque lá está, o homem é o líder e a sócia é a mulher trabalhadora. As qualidades de líder podem-lhe ser reconhecidas mas não são tidas como um dado adquirido como num homem. (Estagiária do 3. ${ }^{\circ}$ ano, 26 anos)

A ideia de superação individual propagada nas revistas especializadas, na publicidade e nos rostos do pós-feminismo (Medina-Vicent 2019, McRobbie 2009) estão muito presentes nos discursos das jovens advogadas, onde se destaca a ideia de eficiência associada à perfeição que, ao não ser alcançada, é entendida como culpa.

Acho que se uma pessoa for supereficiente e se sentar e não se levantar até à hora de almoço e se sentar depois de almoço sem se levantar acho que é possível. Há uma parte que a culpa é minha, sei que podia ser mais eficiente. (Associada, 27 anos)

A planificação da carreira profissional tem em conta a ideia de sacrifício pessoal, a superação individual de que falam as revistas especializadas de gestão, mas também os modelos de advocacia no feminino.

Sim, de rastos, cansadas, com o filho a acordar de três em três horas, mas é possível. Uma das advogadas com que trabalhei o ano passado num processo gigante, ela tinha sido mãe há oito meses, o filho dela não dormia e ela esteve aqui connosco e às vezes eu estava aqui com o A. e ela estava em casa a mandar emails como nós, mas em casa, a trabalhar de casa. (Associada, 30 anos)

A maternidade é idealizada como um momento de superação, de capacitação individual, a prova de força que alia as competências profissionais, «não vai deixar de ser tão boa advogada» com o ritmo de trabalho e o desejo de ser mãe. 
Uma das minhas melhores amigas está grávida e é uma das melhores advogadas de contencioso. Ela teve a trabalhar até ir de férias e deve ter muito mais horas do que eu porque trabalha que se farta, portanto vai cá ficar até ao último dia de ter a criança de certeza e não vai deixar de ser tão boa advogada por causa disso. (Associada, 30 anos)

\subsection{Flexiplan, género e conciliação entre vida familiar e profissional}

O debate em torno do tema da conciliação entre vida familiar e profissional tem levado as sociedades de advocacia a desenvolver estratégias que garantam a continuidade das mulheres no exercício da profissão, seja através de planos de carreira mais flexíveis ou de programas de promoção de talento feminino. Em algumas sociedades, o problema apresenta-se como mais premente.

Eles agora estão a tentar arranjar carreiras alternativas, sobretudo para as mulheres, por exemplo quando têm filhos porque o número de mulheres com filhos é baixíssimo, o número de mulheres é baixo, o número de mulheres com filhos não existe, é baixo, não é assim tão baixo, mulheres com filhos é que não há. (Associada júnior, 26 anos)

O denominado flexiplan permite que o/a advogado/a se mantenha na sociedade com uma redução nos objetivos o que implica uma remuneração mais baixa e uma progressão na carreira mais lenta. Nas palavras de M., uma advogada com dez anos de experiência, este tipo de planos é aceite por mulheres que pretendem conciliar a vida profissional com a maternidade, mas não por homens.

Enquanto instituição, eles tentam fomentar isso e até têm os planos alternativos para quem quer ser mãe ou pai, mas isto nunca foi usado por homens, o chamadoflexiplan, que é, reduzem-te o salário, e reduzem-te o objetivo de horas faturáveis, que tu possas ter uma vida para sair mais cedo... se isso funciona, pode funcionar, efetivamente sais mais cedo, mas não vais participar das operações grandes que exigem pela sua própria natureza ficares lá à noite e ao fim de semana, isso prejudica-te na tua carreira. (Associada principal, 32 anos)

Este tipo de programa tem como resultado óbvio passarmos a encontrar dois tipos de carreira profissional: a primeira, mais esperada, de progressão constante (o career track) até ao topo e uma segunda que irá ser pautada por momentos de estagnação ou até mesmo de retrocesso (o mummy track) (Gronlund e Oun 2018). Esta dualidade pode ser bem incorporada na gestão e organização da sociedade, mas pode causar tensões entre as advogadas e os advogados de um mesmo departamento ou equipa, já que por vezes as relações hierárquicas irão inverter-se. Quem sai da linha de progressão pode rapidamente passar a ser chefiado/a por 
alguém que foi seu estagiário ou estagiária, tendo em consideração que a cada três anos existe uma nova possibilidade de progressão.

Obviamente que, se estive um ano em flexiplan, a minha avaliação vai ser pior, porque eu fiz X horas, não tenho transações, não tenho grandes clientes a ligar, não tenho promoção, mas isso é tido em conta na avaliação e não me prejudica. Os outros estão-me a passar à frente e quando for a minha altura de me querer candidatar, não tenho não só aqueles que já estavam à minha frente como tenho todos os que estavam atrás de mim que já lá estão. (Associada principal, 32 anos)

Do ponto de vista da gestão da sociedade, foram encontradas duas soluções: a advocacia de suporte ${ }^{12}$ - em que a advogada ou advogado assume uma função de apoio a uma equipa integrada/o num departamento - e a gestão de conhecimento, um departamento autónomo criado com o intuito de apoiar todas as áreas de prática.

É um trabalho meticuloso, de pesquisa e esses advogados são mulheres, geralmente. São mulheres que têm preocupação em ser mães, então conseguem ir para aquela área em que dão apoio, não digo administrativo, mas de pesquisa ao advogado que está a trabalhar, mas que não estão ali tão ativamente. (Estagiária de $3 .^{\circ}$ ano, 26 anos)

Neste caso, trata-se de responder à necessidade crescente de acesso à informação e de melhor acesso e utilização do conhecimento produzido na sociedade. Estas duas soluções são procuradas sobretudo por mulheres que pretendem conciliar a vida profissional com a vida pessoal.

Agora até já tenho um terceiro filho, não me apetece voltar à advocacia nestas circunstâncias, e gosto particularmente porque fazendo aquilo que eu sei fazer e que sempre fiz e que corresponde ao curso que eu tirei, consigo fazê-lo com muita tranquilidade, e depois não vou negar, muitas vezes quando estou a publicar na base de dados os documentos de uma transação e a F. tem operações fantásticas em que participa, fico a pensar «bem, gostava imenso de ter trabalhado nisto», mas é como tudo na vida, nós temos que escolher e pronto, neste momento prefiro ter essa saudade, mas se tivesse a trabalhar como advogada, se calhar ia odiar. (Especialista em gestão do conhecimento, 34 anos)

\subsection{As academias de talento feminino}

Os programas de talento feminino foram apenas encontrados em duas das seis sociedades de advocacia e são dedicados a mulheres numa fase intermédia de

12 Não dirige operações, não participa nas decisões nem na criação de soluções para um problema. 
carreira. A sua criação é descrita como um misto de sensações positivas e negativas. Positivas no sentido em que as organizações assumem o problema da desigualdade de género, que combina estagnação e/ou abandono, a «sangria de mulheres», e negativas porque são entendidas como insuficientes e, acrescento, decididas numa perspetiva de cima para baixo, como resposta à pressão exterior, mas sem participação das envolvidas.

Eu acho que o problema é que eles começaram a ver que o escritório fazia uma sangria de mulheres e, portanto, agora têm um comité de talentos, retenção de talento feminino, porque os masculinos eles já retêm. (...) ainda não estou incluída nessas coisas, mas fazem imensas conferências e coisas, e vão, as mulheres mais velhas vão a Madrid, têm feito imensos seminários, mas não sei, para mim não é suficiente. (Associada, 26 anos)

No entanto, é reconhecido que as iniciativas produziram efeito, com a promoção de uma advogada a sócia.

Ela é muito boa, mas não era um caso óbvio de vai ser sócio, não era, obviamente que estar ali naquele ano, no ano da sua candidatura, no momento em que surge um programa destes, facilitou-lhe imenso a vida, hoje em dia é uma ótima sócia, ainda bem que subiu, se não tivesse havido o programa, possivelmente não tinha subido, para ela funcionou. (Associada principal, 32 anos)

E mostram-se reticentes quanto aos programas dedicados às mulheres nas sociedades de advocacia, que podem suscitar nos homens a ideia de que as mulheres passarão a ser privilegiadas na promoção de carreira pelo simples facto de serem mulheres (não será isto que sempre aconteceu aos homens?).

Estamos aqui todas a queimar sutiãs, também não queremos que isto seja um programa que ponha os homens a olhar para nós. Elas agora, por serem mulheres, estão numa situação mais vantajosa do que nós, porque agora temos que as pôr lá em cima. (Associada Principal, 32 anos).

Esta desconfiança ou receio face à aceitação de um programa que pretende diminuir as assimetrias de género na organização é mais um sintoma da dificuldade e da falta de espaço social que as advogadas têm para discutir os motivos da discriminação de género e fazerem ouvir a sua voz. A expressão «olhar para nós» pode ser interpretada como uma referência à invisibilidade feminina nas sociedades em que, apesar de estarem de forma crescente em maior número, se encontram em número desproporcional nos lugares de topo e de decisão, sendo muitas vezes responsáveis pelo trabalho não visível. 


\section{Conclusões}

As sociedades de advocacia ocupam um espaço central no desenvolvimento do capitalismo à escala global e são perpassadas por discursos de agentes nacionais e internacionais, onde se incluem o feminismo neoliberal e o feminismo transnacional de negócios.

O contexto português revelou dissonâncias com as dinâmicas internacionais. As sociedades de advocacia mostram-se conservadoras, refugiando-se na ideia da promoção pelo mérito sem qualquer referência às desigualdades de género e assumindo a liderança no feminino como algo que podem ensinar para fora através de academias de formação. As sociedades ibéricas são aquelas que promovem planos de igualdade e reconhecem as dificuldades na permanência e promoção de mulheres na profissão. No entanto, os resultados são tímidos e os planos elaborados de cima para baixo, sem a participação direta das advogadas na sua formulação.

Os discursos das advogadas revelam as tensões entre as suas capacidades de agência e a conformidade com os papéis de género e a cultura organizacional dos escritórios. Reproduzem em parte os modelos essencialistas - superação, sacrifício, multitasking - reconhecem as desigualdades de género e desconfiam da capacidade dos programas de promoção e de flexibilidade laboral. O predomínio da competição individual dificulta formas de organização e de debate coletivos.

As academias de talento feminino estão na encruzilhada entre a reprodução e a emancipação das normas sociais e são nesse sentido um bom exemplo para explorar as contradições e os desafios que os movimentos feministas enfrentam. Se, por um lado, publicitam as questões de género e promovem a formação de advogadas, por outro, não questionam os processos de genderização que limitam a capacidade de ação das advogadas e as amarram a papéis de género construídos a partir de estereótipos de submissão e sacrifício.

As diferenças encontradas entre escritórios portugueses e ibéricos suscitam novas questões e a possibilidade de novas pesquisas que aprofundem o papel dos planos de igualdade e o seu potencial emancipatório.

\section{Referências bibliográficas}

Acker, Joan. 1990. «Hierarchies, Jobs, Bodies: A Theory of Gendered Organizations.» Gender and Society 4 (2): 139-158. DOI: https: / / doi.org/10.1177/089124390004002002.

Banet-Weiser, Sarah. 2018. Empowered: Popular Feminism and Popular Misogyny. Durham, NC: Duke University Press. DOI: https:/ / doi.org/10.1515/9781478002772

Banet-Weiser, Sarah, Rosalind Gill, e Catherine Rottenberg. 2019. «Postfeminism, popular feminism and neoliberal feminism? Sarah Banet-Weiser, Rosalind Gill and Catherine Rottenberg in conversation.» Feminist Theory 21 (1): 1-39. DOI: https: / / doi.org/10.11 $77 / 1464700119842555$

Boltanski, Luc, e Ève Chiapello. 1999. Le Nouvel Esprit du Capitalisme. Paris: Gallimard. 
Bolton, Sharon, e Daniel Muzio. 2007. «Can't live with'em; can't live without'em: gendered segmentation in the legal profession.» Sociology, 41 (1): 47-64.

Cuatrecasas. 2012. Gender Equality Plan. DOI: https: / / doi.org/10.1177 / 0038038507072283.

Cuatrecasas. 2018. Memoria Corporativa. Disponível em: https://indd.adobe.com/view/ c6e07a28-2791-4449-b367-0b07ba835637

Dezalay, Yves, e David Sugarman. 1995. Professional Competition and Professional Power. London: Routledge.

Elias, Juanita. 2013. «Davos woman to the rescue of global capitalism: Postfeminist politics and competitiveness promotion at the World Economic Forum.» International Political Sociology 7 (2). DOI: https: / / doi.org/10.1111/ips.12015

Faulconbridge, James, e Daniel Muzio, 2008. «Organizational Professionalism in Globalizing Law Firms.»Work, Employment and Society 22: 7-25. DOI: https:// doi.org/10.1177/ 0950017007087413

Faulconbridge, James, e Daniel Muzio, 2012. «Professions in a globalizing world: Towards a transnational sociology of the professions.» International Sociology 27 (1): 136-152. DOI: https:/ / doi.org/10.1177/0268580911423059

Fraser, Nancy. 2016. «Progressive Neoliberalism versus Reactionary Populism: A Choice that Feminists Should Refuse.» Nordic Journal of Feminist and Gender Research 24(4), 281-284. DOI: https: / / doi.org/10.1080/08038740.2016.1278263

Galanter, Marc, e William Henderson, 2008. «The elastic tournament: a second transformation of the big law firm.» Stanford Law Review 60: 1867-1929.

Goldman Sachs. 2009. The Power of the Purse: Gender Equality and Middle-Class Spending. Global Markets Institute. [Disponível em https:/ / www.goldmansachs.com/insights / investing-in-women/bios-pdfs / power-of-purse.pdf]

Gronlund, Anne, e Ida Oun. 2018. «Beyond the Mummy Track? Part-time Rights, Gender, and Career-Family Dilemmas.» Nordic journal of working life studies 8 (3): 177-199. DOI: https:/ / doi.org/10.18291/njwls.v8i3.109546

Hanlon, Gerard. 1998. «Professionalism as enterprise: service class politics and the redefinition of professionalism.» Sociology, 32 (1):43-63.DOI:https: / / doi.org / 10.1177 / 00380385803 2001004

IFLR1000. 2020. Women Leaders 2020 - Europe, Middle East and Africa. Disponível em: https: / / www.iflr1000.com / NewsAndAnalysis / IFLR1000-Women-Leaders-2020-EuropeMiddle-East-and-Africa/Index/10843

Kohll, Alan. 2019. «Why Your Company Should Offer Fertility Benefits.» Forbes 10 de abril. Disponível em: https:/ / www.forbes.com/sites/alankohll/2019/04/10/why-yourcompany-should-offer-fertility-benefits / \#4d8846117699

Larson, Magali. 1977. The Rise of Professionalism: A Sociological Analysis. Berkeley, CA: University of California Press.

McDowell, Linda. 2010. «Capital Culture Revisited: Sex, Testosterone and the City.» International Journal of Urban and Regional Research 34 (3): 652-658. DOI: https://doi.org/ 10.1111/j.1468-2427.2010.00972.x.

McRobbie, Angela. 2009. The Aftermath of Feminism: Gender, Culture and Social Change. London: SAGE.

Medina-Vicent, Maria. 2019. «Feminismo vs Neoliberalismo: una reflexión crítica sobre el liderazgo empresarial de las mujeres.» Athenea Digital 19 (2), e2441. DOI: https: / doi. org/10.5565/rev/athenea.2441.

Pierce, Jennifer. 1996. Gender trials: Emotional lives in contemporary law firms. Oakland, CA: Universtiy of California Press. DOI: https: / / doi.org/10.1525/ california/97805202010 71.001.0001. 
PLMJ. 2015. Relatório de Responsabilidade Social Corporativa 2013-2014. Disponível em: https: / / www.plmj.com / xms / files / v1_antigos_anteriores_a_abr2019/ Artigos_e_ Publicacoes/2014/Relatorio_Responsabilidade_Social_PLMJ_FINAL.pdf

Roberts, Adrienne. 2012. «Financial Crisis, Financial Firms... And Financial Feminism? The rise of 'Transnational Business Feminism' and the necessity of Marxist-Feminist.» IPE, Socialist Studies 8 (2): 85-108. DOI: https:/ / doi.org/10.18740/S40W2K.

Rottenberg, Catherine. 2014. «Happiness and the Liberal Imagination: How Superwoman Became Balanced.» Feminist Studies 40 (1): 144-168.

Rottenberg, Catherine. 2017. «Neoliberal Feminism and the Future of Human Capital.» Signs: Journal of Women in Culture and Society 42 (2): 329-348. DOI: https: / / doi.org/ $10.1086 / 688182$.

Santos, Susana. 2017. «Os estágios profissionais em grandes sociedades de advocacia: contributo para o estudo das formas de socialização profissional». I Encontro da Sessão Temática Sociologia do Direito e da Justiça. CES Contexto 19: 341-353.

Santos, Susana. 2018. «Becoming a lawyer in a large law firm: the idea of the unstoppable worker.» Professions and Professionalism 8 (3). DOI: https:/ / doi.org/10.7577/ pp.2285.

SRS. 2018. Relatório de Responsabilidade Social 2017. Disponível em: https:/ / www.srslegal .pt/pt/a-sociedade/ responsabilidade-social/

Uría Menendez, 2018. Relatório de Sustentabilidade. Disponível em: https: / www.uria.com/ dam/jcr:b13d292b-61d0-4352-882f-6c4ea149b0c0/UM-RSC-2018-POR.pdf

VdA. 2019. Relatório de Responsabilidade Social Corporativa. Disponível em: https:/ / www. vda.pt/pt/media/ pro-bono/relatorio-de-responsabilidade-social-corporativa2019/22232/

Walsh, Janet. 2012. «Not Worth the Sacrifice? Women's aspirations and career progression in law firms.» Gender, Work and Organization 19 (5): 508-531.

Wilkins, David, e Mitu Gulati. 1996. "Why Are There So Few Black Lawyers in Corporate Law Firms? An Institutional Analysis.» California Law Review 84: 493-541. DOI: https: / / doi.org/10.15779/Z382B0H

Wittenberg-Cox, Avivah. 2020. «What Do Countries with the Best Coronavirus Responses Have In Common? Women Leaders.» Forbes 13 de abril. Disponível em: https:/ / www.forbes.com/sites/avivahwittenbergcox/2020/04/13/what-do-countries-withthe-best-coronavirus-reponses-have-in-common-women-leaders / \#6ac9e21b3dec.

Susana Santos. Doutorada em Sociologia. Investigadora integrada no Cies.Iscte, Centro de Investigação e Estudos em Sociologia e professora auxiliar convidada na Escola de Sociologia e Política Públicas do ISCTE - Instituto Universitário de Lisboa. Os seus temas de investigação têm-se centrado em torno da formação de elites transnacionais no campo da advocacia e na formação de esferas públicas em diferentes contextos, com particular interesse pela produção discursiva.

Endereço eletrónico: susanacsantos@iscte.pt

Artigo recebido em 30 de junho e aceite para publicação em 7 de outubro de 2020. 